\title{
A high COPD assessment test score may predict anxiety in COPD
}

This article was published in the following Dove Press journal: International Journal of COPD

\author{
Hilman Harryanto' \\ Sally Burrows ${ }^{2}$ \\ Yuben Moodley ${ }^{1,2}$ \\ 'Department of Respiratory Medicine, \\ Fiona Stanley Hospital, Perth, WA, \\ Australia; ${ }^{2}$ Faculty of Health and \\ Medical Sciences, Medical School, \\ University of Western Australia, \\ Perth, WA, Australia
}

Correspondence: Hilman Harryanto Department of Respiratory Medicine, Fiona Stanley Hospital, I I Robin Warren Drive Murdoch WA 6150, WA, Australia Email hilman.harryanto@gmail.com

\section{Introduction}

The prevalence of anxiety is $55 \%$ in patients with COPD, ${ }^{1}$ and it is associated with worse disease control. Therefore, early recognition and institution of treatment of this comorbidity significantly improve patient's quality of life. Recently, a questionnaire called the COPD assessment test (CAT) has been incorporated into the Global Initiative for Chronic Obstructive Lung Disease (GOLD) guidelines for the management of COPD, and a higher score is associated with increased COPD symptoms. ${ }^{2}$ Considering the regular use of CAT, it was evaluated whether this tool can also be used to identify anxiety. The CAT score was correlated with the Hospital Anxiety and Depression Scale (HADS) to determine the level at which CAT may predict anxiety.

\section{Materials and methods}

The study was approved by the Human Research Ethics Committee of the Royal Perth Hospital (HREC study 2012/055), with a waiver given for patient consent. All patient data remained confidential. Clinical data were collected from 100 patients with confirmed COPD, who attended the COPD outreach clinic, of whom 78 patients completed spirometry. COPD severity was graded according to the GOLD criteria, and the CAT and HADS scores were collected on 2 consecutive consultations separated by 6 months with a $100 \%$ completion rate. The severity of the cohort was classified as GOLD 1 (2 patients), GOLD 2 (29 patients), GOLD 3 (39 patients) and GOLD 4 (8 patients). A total of 45 patients had clinically significant anxiety on the first visit and 38 patients on the second visit as per HADS. The prevalence of anxiety in COPD GOLD 1 is $0 \%$, GOLD 2 is 45\% (13), GOLD 3 is 56\% (22) and GOLD 4 is $38 \%$ (3) in visit 1 . Data from the second visit were similar, apart from the decreased prevalence in GOLD $3(13,43 \%)$ and the increased prevalence in GOLD $4(6,67 \%)$.

\section{Results}

A CAT score was found to have significant correlation with anxiety with an OR of 1.25 (95\% CI 1.13-1.4). At each visit, the CAT score could discriminate between those with anxiety and those without. In visit 1 , area under receiver operating characteristic curve was 0.74 (95\% CI $0.64-0.84)$, and in visit 2, area under the receiver operating characteristic curve was 0.76 (95\% CI $0.66-0.85)$. A CAT cutoff score of $\geq 20$ gives a sensitivity of $80 \%$ and $84 \%$ and an acceptable specificity of $52 \%$ and $47 \%$ in visit 
1 and visit 2, respectively (Table 1). The change in FEV1 from visit 1 to visit 2 did not correlate with the change in $\operatorname{CAT}\left(R^{2}=0.03\right)$, which is an interesting observation requiring further investigation. These pilot data suggest that CAT may identify patients with anxiety and form the basis for future studies with a larger sample size.
Table I (Continued)

\begin{tabular}{lll}
\hline Cutoff & Sensitivity (\%) & Specificity (\%) \\
\hline$\geq 15$ & 93.02 & 28.07 \\
$\geq 16$ & 93.02 & 29.82 \\
$\geq 17$ & 93.02 & 36.84 \\
$\geq 18$ & 88.37 & 40.35 \\
$\geq 19$ & 86.05 & 42.11 \\
$\geq 20$ & 83.72 & 47.37 \\
$\geq 21$ & 83.72 & 50.88 \\
$\geq 22$ & 81.40 & 59.65 \\
$\geq 23$ & 74.42 & 66.67 \\
$\geq 24$ & 62.12 & 75.44 \\
$\geq 25$ & 48.84 & 80.70 \\
$\geq 26$ & 39.53 & 84.21 \\
$\geq 27$ & 37.21 & 85.96 \\
$\geq 28$ & 34.88 & 89.47 \\
$\geq 29$ & 27.91 & 92.98 \\
$\geq 30$ & 27.91 & 98.25 \\
$\geq 31$ & 23.26 & 98.25 \\
$\geq 33$ & 16.28 & 98.25 \\
$\geq 34$ & 13.95 & 100.00 \\
$\geq 35$ & 9.30 & 100.00 \\
$\geq 36$ & 6.98 & 100.00 \\
$\geq 38$ & 2.33 & 100.00 \\
\hline
\end{tabular}

\section{Conclusion}

This study suggests that anxiety must be specifically investigated in COPD patients, especially with a CAT score of $\geq 20$. Further analysis with a larger sample size should further evaluate the value of CAT score correlation with anxiety in COPD patients.

\section{Disclosure}

The authors report no conflicts of interest in this work.

\section{References}

1. Yohannes AM, Willgoss TG, Baldwin RC, Connolly MJ. Depression and anxiety in chronic heart failure and chronic obstructive pulmonary disease: prevalence, relevance, clinical implications and management principles. Int J Geriatr Psychiatry. 2010;25(12):1209-1221.

2. Hilmarsen $\mathrm{CW}$, Wilke S, Engan H, et al. Impact of symptoms of anxiety and depression on COPD assessment test scores. Eur Respir J. 2014;43(3):898-900. 
International Journal of COPD

\section{Publish your work in this journal}

The International Journal of COPD is an international, peer-reviewed journal of therapeutics and pharmacology focusing on concise rapid reporting of clinical studies and reviews in COPD. Special focus is given to the pathophysiological processes underlying the disease, intervention programs, patient focused education, and self management protocols.

This journal is indexed on PubMed Central, MedLine and CAS. The manuscript management system is completely online and includes a very quick and fair peer-review system, which is all easy to use. Visit http://www.dovepress.com/testimonials.php to read real quotes from published authors 